\title{
Naplaćeni i nenaplaćeni porezi u Hrvatskoj i Europskoj uniji
}

\author{
MIHAELA BRONIĆ Institut za javne financije
}

Nenaplaćeni porezi u Hrvatskoj posljednjih godina značajnije rastu, pa ih je potrebno uključiti u analize, radi preciznije usporedbe s porezima u EU. Osim toga, Hrvatska ima značajan deficit i visoki javni dug, pa joj je neophodna fiskalna konsolidacija. Državne rashode je trenutno teško smanjivati, a prihodi su prilično neizvjesni. Premda se očekuje dovršetak pregovora s EU, uz velike investicijske projekte i bogatu turističku sezonu, zemlja je i dalje suočena sa značajnom nezaposlenošću i nelikvidnošću zbog čega se državni proračun možda neće puniti u skladu s očekivanjima. Zbog toga bi Ministarstvo financija moralo posebnu pozornost posvetiti što boljem prikupljanju državnih prihoda uključujući i nenaplaćene poreze.

Cilj rada je na temelju najnovijih podataka MMF-a usporediti ukupan porezni teret u Hrvatskoj i u EU u razdoblju od 200o-o9, analizirati sličnosti i razlike u poreznoj strukturi Hrvatske i EU-a, te prikazati iznos nenaplaćenih poreza u Hrvatskoj.

\section{UKUPAN POREZNI TERET}

Prema dostupnim podacima, ukupan porezni teret $\mathrm{u} \mathrm{Hr}$ vatskoj, odnosno udio svih poreza i doprinosa u BDP-u, od 2000-09. bio je malo niži od prosjeka EU-27, te malo viši od prosjeka EU-I2 (grafikon I). ' Ta usporedba, međutim, nije objektivna, jer se u Hrvatskoj porezi prikazuju isključivo u trenutku naplate (gotovinsko načelo), a u većini država EU-a prikazuju se čim nastanu, bez obzira jesu li

I EU-I2 čine Cipar, Bugarska, Češka, Estonija, Latvija, Litva, Mađarska, Poljska, Rumunjska, Slovačka, Slovenija i Malta, a EU-27 su sve članice Europske unije. naplaćeni (obračunsko načelo). ${ }^{2}$ To znači da u podacima za Hrvatsku nisu prikazani nenaplaćeni porezi, a u podacima za EU jesu, te da bi ukupan porezni teret u Hrvatskoj bio nešto viši od prikazanog u grafikonu I, kada bi se porezi prikazivali na isti način.

\section{POREZNA STRUKTURA}

Važan element usporedbe poreza u EU i Hrvatskoj je i struktura poreza (udio određene vrste poreza u ukupnim poreznim prihodima). Struktura ukupnih poreznih prihoda u Hrvatskoj značajnije se razlikuje od prosjeka EU-27 i nešto manje od prosjeka EU-I2 (grafikon 2). Svugdje dominiraju doprinosi, ali je u Hrvatskoj i EU-I2 snažnije izraženo oporezivanje potrošnje (uglavnom PDV-om), a u zemljama EU-27 oporezivanje dohotka.

Važno je napomenuti i da je u razdoblju od 200o-og. udio prihoda od poreza na potrošnju (PDV, trošarine i ostali porezi na potrošnju), $u$ ukupnim poreznim prihodima $u$ EU-27 rastao, dok se u Hrvatskoj smanjivao (grafikon 3).

\section{NENAPLAĆENI POREZI}

Prema dostupnim podacima, ukupno (kumulativno) nenaplaćeni porezi ${ }^{3}$ u Hrvatskoj 2OIo. iznosili su oko 12 mlrd. kuna, a ukupno nenaplaćeni doprinosi oko 2 mrld. kuna (grafikon 4). To je oko I3\% od ukupno naplaćenih poreza i doprinosa u 20Io. Budući da prema Općem poreznom za-

2 U zemljama EU-a samo se u Bugarskoj, Češkoj i Sloveniji porezi i doprinosi prikazuju prema gotovinskom načelu (IMF, 2OII).

3 Ovdje su prikazani samo nenaplaćeni porezi i doprinosi za koje je Porezna uprava pokrenula postupak ovrhe, a ne i oni za koje taj postupak nije pokrenut. 


\section{Grafikon I.}

Ukupni porezi i doprinosi konsolidirane opće države (\% BDP-a, tekuće cijene)

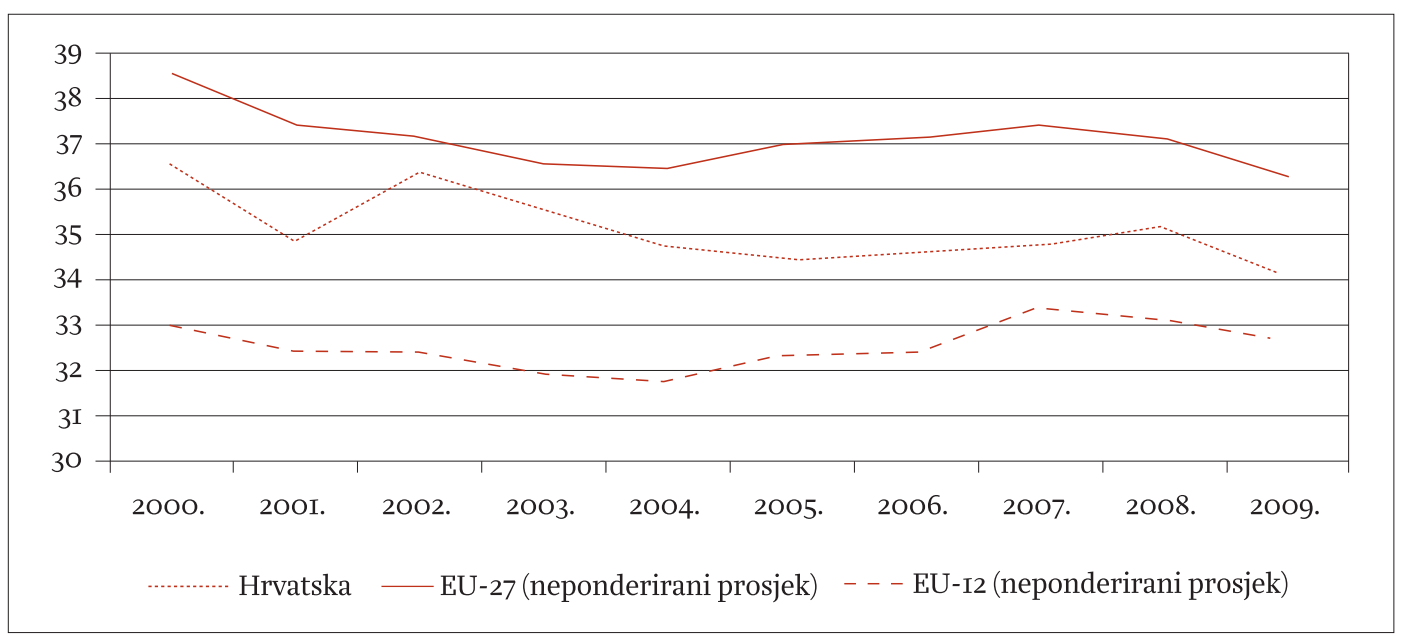

Izvor: obrada autorice na temelju podataka MMF-a (2OII)

\section{Grafikon 2.}

Ukupni porezni prihodi konsolidirane opće države, 2009. (u \%)

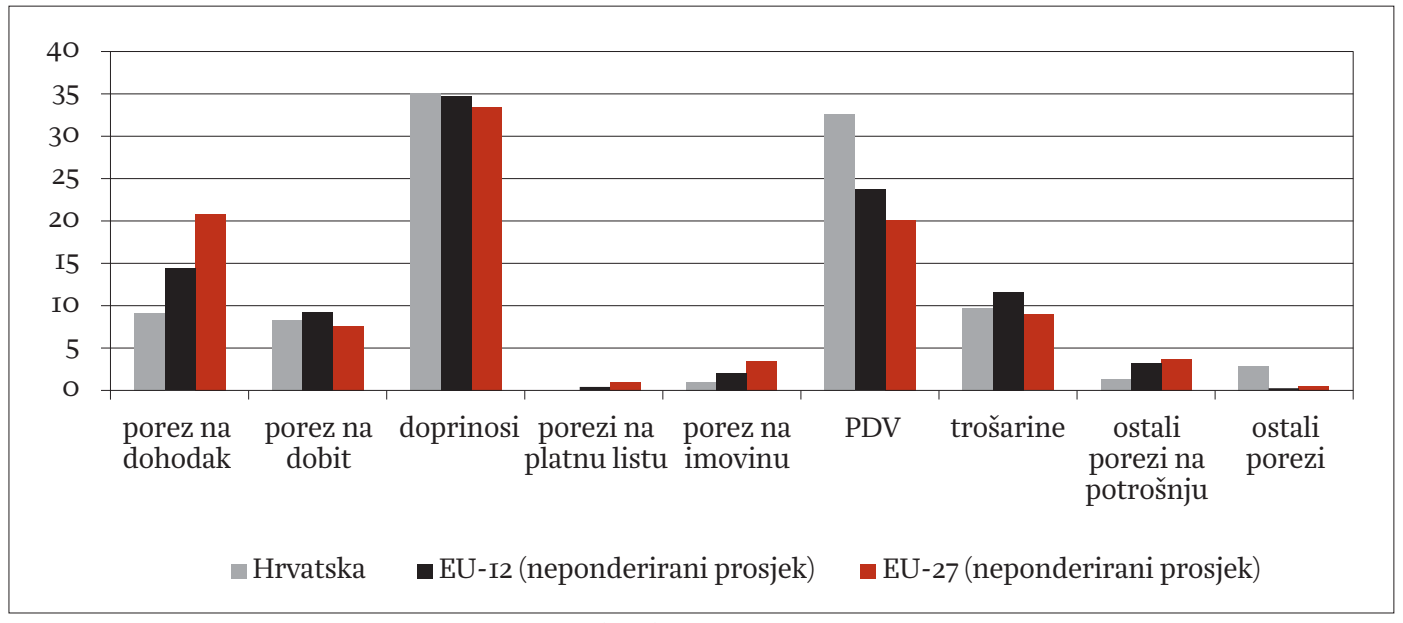

Izvor: obrada autorice na temelju podatka MMF-a (2OII)

\section{Grafikon 3.}

Porezi na potrošnju u ukupnim poreznim prihodima konsolidirane opće države (u \%)

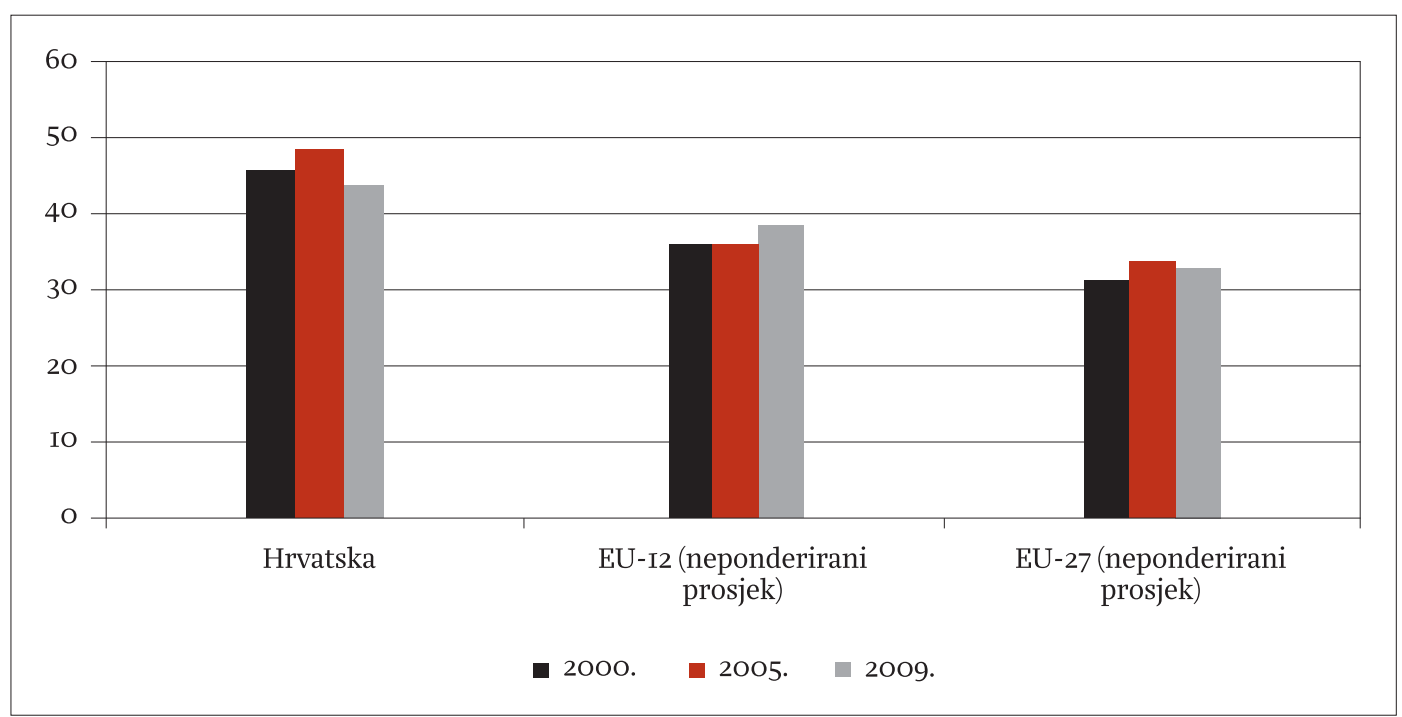

Izvor: obrada autorice na temelju podatka MMF-a (2OII) 
konu (čl. 96) apsolutni rok zastare za utvrđivanje porezne obveze i kamata te njihovu naplatu nastupa šest godina od dana kada je zastara počela prvi put teći, vjerojatno bi dio prikazanih nenaplaćenih poreza i doprinosa trebalo otpisati. I u državama EU-a prikazuju se samo oni porezi i doprinosi za koje se realno drži da će biti naplaćeni.

Na temelju dostupnih kumulativnih iznosa nenaplaćenih poreza i doprinosa (grafikon 4), moguće je izračunati godišnje promjene nenaplaćenih poreza i doprinosa (grafikon 5). Nenaplaćeni porezi i doprinosi značajnije su porasli 2009. i 20IO. (svake godine više od 3 mlrd. kuna).
Iz te perspektive pohvalno je izglasavanje Zakona o posebnoj mjeri naplate poreznog duga uzrokovanog gospodarskom krizom. Njime se određenim obveznicima, koji trenutno ne mogu plaćati poreze, omogućuje reprogramiranje poreznog duga. Međutim, kriteriji po kojima će Ministarstvo financija nekome odobravati reprogramiranje poreznog duga, a nekome neće, nisu u potpunosti jasni. Kako će Ministarstvo financija moći utvrditi je li dug koji se odgađa posljedica krize? U Zakonu piše da je reprogramiranje moguće za dug nastao do 3I. prosinca 2OIO, ali ne i od kojeg vremenskog razdoblja do tog roka. Stoga bi taj, ali i druge kriterije trebalo detaljnije razradi-

\section{Grafikon 4.}

Kumulativni nenaplaćeni porezi i doprinosi u Hrvatskoj (u mlrd. kn)

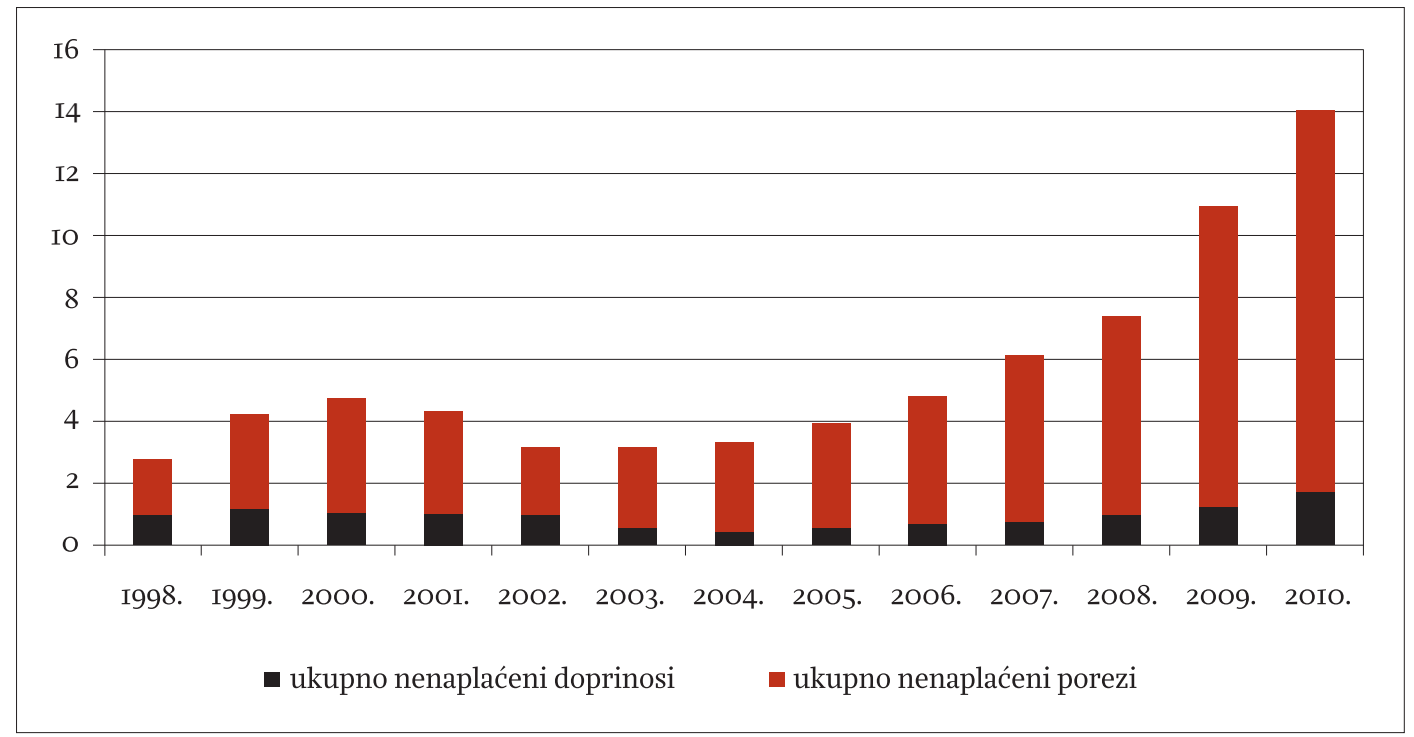

Napomena: Podaci za svaku godinu prikazani su na datum 3I. prosinca.

Izvor: obrada autorice na temelju podataka FINA-e (2OII)

Grafikon 5.

Godišnje povećanje/smanjenje nenaplaćenih poreza i doprinosa u Hrvatskoj (u mlrd. kn)

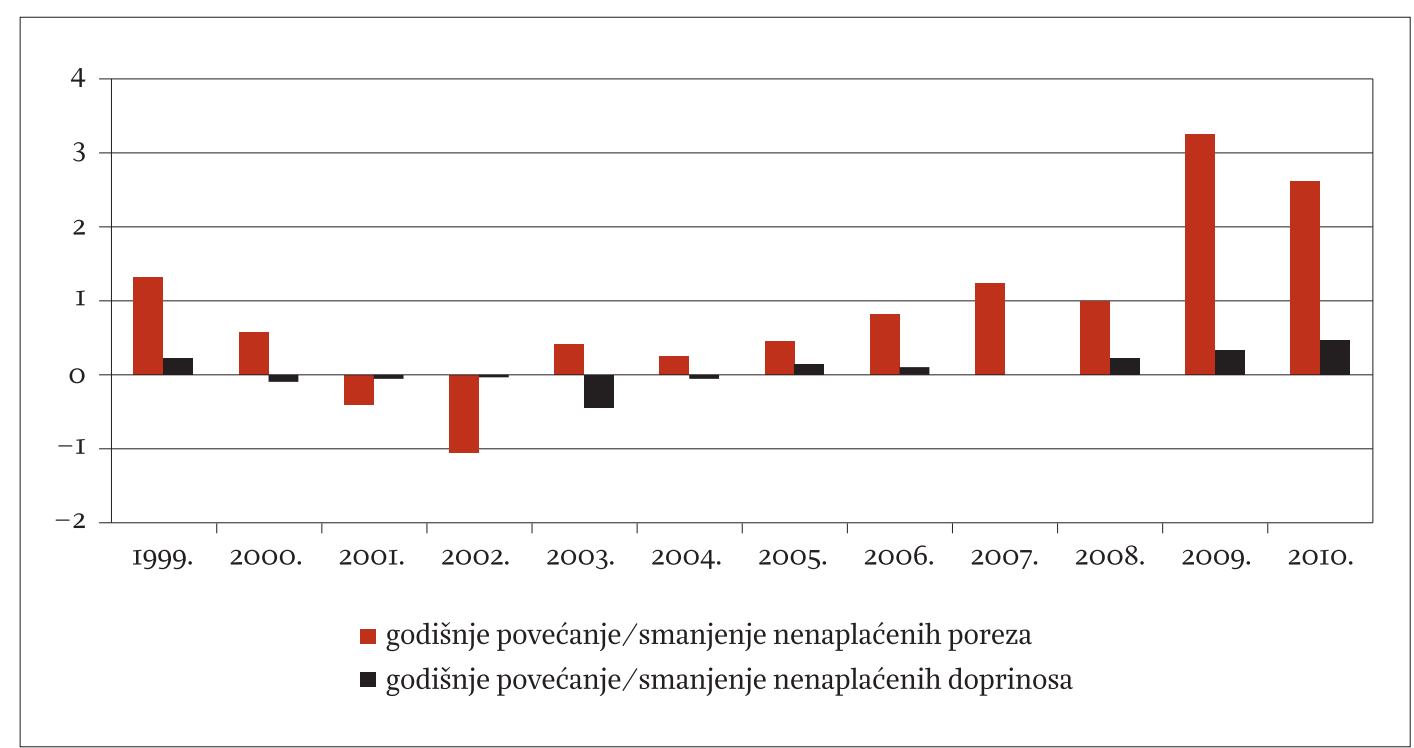

Izvor: obrada autorice na temelju podatka FINA-e (2OII) 
ti i objaviti. Također, radi poboljšanog punjenja državnog proračuna, Ministarstvo financija treba što prije istražiti i ostale slučajeve neplaćanja poreza (koji nisu uzrokovani krizom), utvrditi tko i zašto ne plaća poreze i doprinose, te svim raspoloživim načinima pokušati smanjiti i naplatiti i ta dugovanja, ali i pokušati spriječiti nastanak novih.

\section{ZAKLJUǦAK}

Usporedba poreza u Hrvatskoj i EU pokazala je sljedeće:

- Ukupan porezni teret u razdoblju od 2000-o9. u Hrvatskoj bio je malo niži od prosjeka EU-27, te malo viši od prosjeka EU-I2. Međutim, u podacima za Hrvatsku nisu uključeni nenaplaćeni porezi i doprinosi, a u podacima za EU jesu.

- Uključivanjem podataka o nenaplaćenim porezima i doprinosima, za koje se realno očekuje da će biti naplaćeni, ukupan porezni teret u Hrvatskoj bio bi veći od prikazanog u grafikonu I. Moguće je da bi se i porezna struktura donekle izmijenila.

- U Hrvatskoj je naglasak na oporezivanju potrošnje, što je i trend u EU-I2.

- Ministarstvo financija treba objaviti podrobnije podatke o nenaplaćenim porezima i doprinosima (prikazati pojedinačne nenaplaćene iznose za svaku vrstu poreza i doprinosa, te objaviti koji je dio nenaplaćenih poreza i doprinosa zastario i otpisati ih).

- Ministarstvo financija moralo bi veću pozornost posvetiti što boljem prikupljanju državnih prihoda (uključujući i nenaplaćene poreze i doprinose) kako bi se kontrolirao i pokušao smanjiti javni dug i deficit.

- Dobro je da je izglasan Zakon o posebnoj mjeri naplate poreznog duga uzrokovanog gospodarskom krizom kojim se određenim poreznim obveznicima omogućuje reprogramiranje poreznog duga. Neophodno je, međutim, detaljnije razraditi i obznaniti kriterije po kojima će Ministarstvo financija odlučivati o reprogramiranju.

- Potrebno je istražiti i ostale slučajeve neplaćanja poreza (kod kojih uzrok nije kriza), utvrditi tko i zašto ne plaća poreze i doprinose, te ih pokušati smanjiti i naplatiti, ali i spriječiti nastanak novih dugovanja takve vrste.

\section{LITERATURA}

FINA, 20II. Broj insolventnih pravnih i fizičkih osoba, broj zaposlenih, iznos nepodmirenih naloga za plaćanje [online]. Dostupno na: [http://hgk.biznet.hr/hgk/fileovi/209I2.xls].

Ministarstvo financija, 20Io. Mjesečni statistički prikaz, br. I8o [online]. Dostupno na: [http://www.mfin.hr/ adminmax/docs/I80\%20rujan\%2O2OIo_hrv.pdf]. Zagreb: Ministarstvo financija.

Ministarstvo financija, 20II. Uputa o načinu obrade zahtjeva i provođenja postupka za odobravanje i provedbu reprograma naplate poreznog duga [online]. Zagreb: Ministarstvo financija. Dostupno na: [http://www.porezna-uprava.hr/DugackaVijest.asp?idVijesti=II56].

IMF, 20II. GFS March $20 I I$ [online]. Washington: International Monetary Fund. Dostupno na: [http://www. imfstatistics.org/imf/].

Opći porezni zakon, NN I47/o8 i I8/II. Zagreb: Narodne novine.

Zakon o posebnoj mjeri naplate poreznog duga uzrokovanog gospodarskom krizom, NN 45/II. Zagreb: Narodne novine. 